\title{
Percepções de professores sobre saúde vocal e trabalho
}

\author{
The teachers's perceptions on vocal health and work
}

Regina Zanella Penteado

Pós-doutoranda em Educação pela Universidade Estadual Paulista Júlio de Mesquita Filho - UNESP/ Rio Claro(SP). Doutora em Saúde Pública pela Faculdade de Saúde Pública da Universidade de São Paulo rzpenteado@unimep.br

Tania Maestrelli Ribas Mestre em Ciências da Saúde pela Universidade Federal de Goiás mctulianpg@gmail.com

Marco Túlio A. García-Zapata Doutorado em Infectologia e Medicina Tropical pela Universidade Federal de Goiás mctulianpg@ gmail.com
RESUmo As percepções de professores em relação à voz/saúde vocal e trabalho docente são importantes e merecem atenção nas pesquisas com educadores. Este é um estudo qualitativo que envolve um grupo focal com vinte professores de ensino fundamental de três escolas públicas de Goiânia (GO). Foram identificadas quatro categorias temáticas: a) percepções sobre a voz; b) cuidados com a voz; c) uso da voz na profissão; e d) condições e organização do trabalho docente. Há necessidade de ampliação da percepção sobre a voz no processo de ensino-aprendizagem e de formação de cultura de cuidado e de saúde do professor nos contextos da formação inicial (licenciaturas) e continuada. Investimentos são necessários nos setores de saúde e de educação para que as questões da voz, da expressividade, do cuidado e da saúde do professor sejam sistematizadas nas políticas e práticas voltadas para a melhoria da formação do educador, das relações educativas e das condições e qualidade do trabalho docente e do ensino.

Palavras-chave: Educação; Voz; Promoção da Saúde; Fonoaudiologia; Saúde Coletiva; Trabalho Docente.

Aвstract The teachers' perception of their voice/vocal health and their jobs is important and should be focused by studies involving educators. This qualitative study involves a focus group of 20 teachers from three public elementary schools of Goiânia (GO). Four theme categories were identified: a) the perceptions about voice, b) vocal care, c) the professional use of voice, and d) the teaching conditions and work organization. The voice's role in the teaching-learning process should be better understood in order to create a culture of self-care and health among teachers and it should occur within educational practices in initial education (Bachelor's Degree) and ongoing training. Investments should be made in the fields of Health and Education, so that issues regarding the teachers' voice, expressiveness, care and health can be standardized in public policies and practices directed towards the improvement of professional teacher training, educational relationship, work quality.

Keywords: Education; Voice; Health Promotion; Speech-Language and Hearing Sciences; Collective Health; Teaching WORK. 


\section{INTRODUÇÃO}

A categoria docente é a que mais apresenta distúrbios vocais decorrentes do uso da voz na profissão e a que tem maior risco de desenvolver problemas vocais de origem ocupacional. ${ }^{1-7}$

Em decorrência da alta prevalência de alterações vocais em professores, a literatura apresenta-se vasta em estudos com enfoque epidemiológico sobre a voz do professor; entretanto, não vem ao caso apresentá-los neste artigo.

Cabe, no entanto, ressaltar que poucos estudos buscam compreender as relações entre voz, trabalho e processo saúde-doença-cuidado docente a partir de metodologias qualitativas.

As metodologias qualitativas permitem aflorar os sentimentos, as experiências e as percepções dos sujeitos, ${ }^{8,9}$ por isso se fazem adequadas e pertinentes em estudos que focalizam o modo como as pessoas percebem, significam e atribuem sentidos às experiências e à realidade vivida.

Um estudo ${ }^{10}$ identificou mudanças positivas nas percepções sobre a voz de educadoras de uma creche de São Paulo (SP) após um treinamento vocal.

O impacto de grupos de vivência de voz foi investigado nas percepções de professores de ensino fundamental de uma escola pública de Piracicaba (SP). ${ }^{11} \mathrm{O}$ estudo evidenciou percepções sobre a voz e os processos saúde-doença a ela relacionados, bem como sobre o ambiente e as condições de trabalho. Também possibilitou identificar situações que prejudicam a qualidade da voz, a interação professor-alunos e a relação educativa.
Um estudo com professores do ensino médio da rede estadual de Rio Claro (SP) ${ }^{12}$ indicou sua dificuldade em perceber o processo saúde-doença vocal e evidenciou a interferência das condições e organização do trabalho docente, que impactam negativamente na subjetividade do professor, na qualidade do trabalho e na qualidade de vida.

Outro estudo envolveu professores do ensino fundamental de uma escola particular de Piracicaba (SP $)^{13}$ e evidenciou problemas no trabalho docente que geram tensões e sentimentos negativos. Relatou, também, que os professores têm dificuldade para perceber e relacionar a saúde vocal aos hábitos, comportamentos e condições de trabalho. ${ }^{13}$

Pesquisas internacionais também confirmam a escassez de estudos voltados à percepção de professores sobre a voz. ${ }^{14}$

O objetivo da presente pesquisa foi analisar as percepções de professores em relação à saúde vocal e trabalho docente.

\section{MÉTOdo}

Este estudo de caráter qualitativo teve por sujeitos vinte professores (14 mulheres e 6 homens) do ensino fundamental de três escolas da rede estadual de educação de Goiânia (GO), em 2011, com aprovação CEP/UFG 308/2010 de 28 de fevereiro de 2011. Todos os sujeitos assinaram o Termo de Consentimento Livre e Esclarecido.

O critério de inclusão no estudo foi ser professor do ensino fundamental da rede estadual de educação de Goiânia (GO), estar em exercício profissional em três escolas específicas no ano de 2011 e apresentar, no mínimo, três queixas enquadradas no protocolo de queixas vocais. ${ }^{15}$ As escolas parti- 
cipantes da pesquisa contaram com a abertura da direção para a realização do estudo, mediante sua concordância e autorização.

Foram excluídos do estudo os professores que se encontravam sob licença médica, licença-prêmio, afastados da escola, da função ou readaptados, bem como os que não apresentaram a queixa isolada de fadiga vocal e/ou até três queixas constantes protocolo de queixas vocais.

Os dados acerca das percepções de professores sobre saúde vocal e trabalho docente foram obtidos por meio da participação dos sujeitos em um grupo focal: um encontro que inclui questões pré-planejadas e orientadas pelo pesquisador e que, por meio da interação e dos diálogos entre os participantes em um ambiente acolhedor, possibilita a expressão de percepções, sentimentos, valores, ideias e representações individuais e coletivas. ${ }^{16}$

$\mathrm{O}$ pesquisador dirigiu o grupo focal em uma das escolas envolvidas, contando com três encontros de cinquenta minutos cada.

As questões que orientaram os diálogos e discussões focalizaram o trabalho docente e as relações deste com a saúde e a qualidade de vida do professor. Cabe esclarecer que a escolha das questões deu-se em função dos aspectos de interesse do estudo e não seguiu protocolo algum.

As questões que orientaram as discussões do primeiro encontro foram: "O que pensam sobre o uso da voz na profissão?" (envolvendo aspectos do ambiente e da organização do trabalho docente que influenciam no desempenho do professor) e "O que você acha da sua voz?". No segundo encontro as questões foram: "Vocês sabem como a voz é produzida?" e "Que cuidados vocês têm com a voz"? E, por fim, no terceiro encontro: "Fale sobre a qualidade das relações interpessoais, a autonomia do professor e os impactos destes na saúde".

Os encontros foram filmados com uma filmadora digital Sony DSC-W350 e as discussões gravadas foram transcritas. As transcrições foram submetidas à análise de conteúdo/análise temática de Bardin, ${ }^{17}$ na qual, primeiramente, é realizada a leitura flutuante (inicial), na tentativa de apreender, de uma forma global, as ideias fundamentais e seus significados gerais; em seguida, é feita a seleção das unidades de sentido, escolhendo-se frases ou parágrafos significativos que permitam a classificação em temas e conjuntos temáticos.

\section{Resultados}

Os sujeitos envolvidos apresentam idades entre 20 e 50 anos (20 a 30 anos - oito professores; 31 a 50 anos - seis professores; e mais de 50 anos - seis professores). Eles cumprem carga horária semanal de trabalho de quarenta horas em uma única escola; e o tempo de magistério variou de 9 a 25 anos.

Os resultados foram organizados e apresentados em categorias e conjuntos temáticos e, em seguida, apresentados resultados de alguns trechos discursivos correspondentes às categorias e conjuntos temáticos reconhecidos. A identificação dos participantes é feita de forma numérica e entre parênteses - por exemplo, P1: Professor 1.

A análise possibilitou identificar as percepções dos professores sobre as questões abordadas: uso da voz na profissão, produção vocal e questões relacionadas às condições e organização do trabalho docente.

Por meio da análise de conteúdo foi possível identificar quatro categorias e seus respectivos conjuntos temáticos (Figura 1). 
Figura 1 - Categorias da análise de conteúdo e seus respectivos conjuntos temáticos

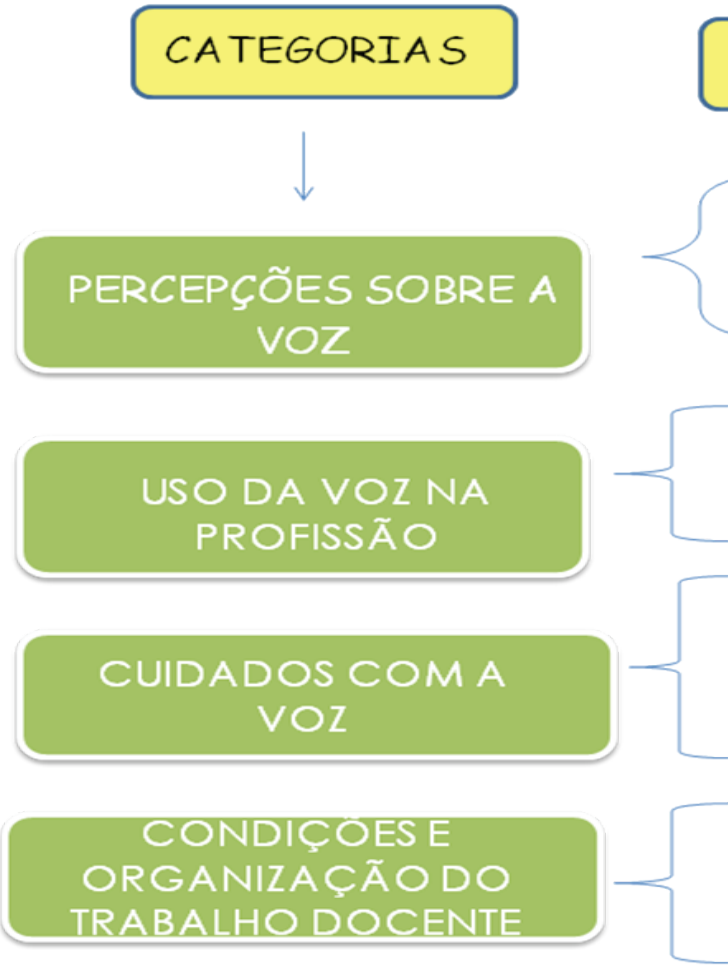

Fonte: Elaborado pelas autoras

A seguir foram descritos os trechos discursivos correspondentes às categorias e conjuntos temáticos reconhecidos. Cabe observar que aspectos distintos no âmbito de uma mesma problemática ou categoria foram organizados e apresentados em parágrafos diferentes.

\section{Percepções sobre a voz}

a) Positivas

P3: "Me vejo forte e resistente quanto à voz. Não tenho dificuldade [...]. Nunca perdi a voz".

b) Negativas e queixas vocais

P 1: "Sinto cansaço no final do dia. Falta de ar".

\section{Conjuntos temáticos}

- Percepções positivas,

- Percepções negativase queixas vocais

\section{Hipersolicitação vocal}

\section{- hidratação}

- redução de abusos

- mudanças nas estratégias de ensino

- diálogo com alunos

- materiais e recursos no trabalho

- desamparo/insegurança

- propostas de mudanças

P2: "As vezes, grito e engasgo, sinto cansaço [...]. Se forçar a voz, fico rouca e começo a tossir. Se falar muito, fico cansada”. P5: Tive que dar um grito e passei mal três dias [...]. O dia [em] que falo alto, minha garganta dói. Minha voz mudou, todos falam... eu acho que é estresse".

P14: “Tem hora que minha voz tá saindo pelo nariz [...] tem hora que faço força para falar [...]. Não consigo cantar, minha voz some, falta ar. Acho minha voz horrível, 'soprosa'”.

P15: "Eu percebo que o excesso de giz atrapalha. Minha voz fica trêmula. [...] mais grave, e isso me incomoda".

P 14: "Não consigo cantar porque falta oxigênio; minha garganta começa a doer". P18: "A minha voz é 'soprosa". 


\section{USO DA VOZ NA PROFISSÃo}

a) Hipersolicitação vocal

P1: "Uso a voz para adequar a disciplina dos alunos, e não para ensinar".

P6: "Alunos agitados [...] às vezes, tem que falar alto para controlar a voz".

P7: "Se você fala baixo, você não é ouvida".

\section{Cuidados Com a voz}

\section{a) Hidratação}

P10: "Tomo água somente em casa”.

b) Redução de abuso vocal (grito)

P3: "No princípio eu gritava; agora me eduquei".

P2: "No início, eu gritava muito e, de um tempo para cá, mudei; e isso melhorou a relação com os alunos".

c) Mudança nas estratégias e recursos de ensino

P1: "Utilizo recursos, como bater no armário, para chamar a atenção dos alunos".

P2: "Divido as aulas entre expositivas e atividades escritas [...] vou até o aluno para chamar a atenção, ao invés de gritar". P7: "Às vezes, brinco de estátua e melhora, mas, às vezes, não".

P14: "Arrumei um aparelho amplificador para falar mais baixo e aumentar minha voz dentro da sala".

P16: "Eu deixei de usar giz para escrever data e meu nome [...]. Antes, eu fazia assim: a sala ia conversando e eu aumentava mais ainda a minha voz. Agora eu não faço nada. Se eles quiserem ouvir, eu falo; se não, fico quietinha”.

\section{CONDIÇÕES E ORGANIZAÇÃ̃o DO TRABALHO DOCENTE}

\section{a) Diálogo com alunos}

P6: "Falamos tanto e eles não prestam atenção. [...] eu gostaria de falar e ser ouvida [...]. Às vezes, eu acho que falo, falo e estou fazendo monólogo".

P1: "A criança atropela a fala do outro e isso atrapalha o raciocínio do professor". P7: "As crianças não têm respeito de esperar o outro falar".

\section{b) Materiais e recursos no trabalho}

P5: "Eu quero dar uma aula prática, mas não tem suporte, não tem laboratório".

P15: "O excesso de giz atrapalha a voz [...] precisamos de quadro de pincel. P10: "No recreio não tem nada; tinha brinquedo, destruíram tudo.

P16: "Não temos a mínima condição de trabalho [...] a educação é uma descrença $[. .$.$] a qualidade de vida do pro-$ fessor é zero".

\section{c) Ambiente de trabalho}

(P2): "Eu não escuto o que eles falam, pois tenho que competir com o ruído".

(P3): "Como as salas são de placa, ouve-se barulho das outras salas ou barulho dos alunos fora da sala" (P11): "Tem o problema dos pombos; cai pó deles encima da mesa."

\section{d) Desamparo e insegurança}

P13: "Às vezes, você não tem apoio dos colegas, as relações ficam difíceis [...]. O professor quer apoio".

P6: "O professor vive 'inseguro'. Como você fica com cinco alunos 'especiais' numa sala de aula?" 
P14: "Se você encostar em um aluno, a mídia cai em cima, mas se um aluno te agride, aí abafa o caso".

\section{e) Propostas de mudança}

P5: "Tinha que ter um grupo de profissionais [...] para a gente ser auxiliado [...] e ter mais participação da comunidade na escola, para melhorar o comportamento dos alunos".

P10: “Talvez relaxamento ou yoga poderiam melhorar o comportamento dos alunos".

P20: "A gente precisa aprender a fazer exercício de voz para evitar problemas futuros".

\section{Discuss Ão}

Os resultados da categoria "percepções sobre a voz" mostram que prevalecem as conotações negativas (1b). A voz é percebida pelos professores, mais em função do seu processo saúde-doença e da presença de queixas, sinais e sintomas vocais do que das possibilidades de expressividade, interação e processo ensino-aprendizagem. Nota-se que, mesmo quando a conotação é positiva (1a), ela se dá em oposição à presença da queixa/problema - "Me vejo forte e resistente quanto à voz. Não tenho dificuldade [...]. Nunca perdi a voz" (P3). Ou seja, as queixas/problemas orientam as percepções sobre a voz docente.

Estudos evidenciam que professores brasileiros apresentam elevado número de sinais e sintomas de voz e apontam a necessidade de cuidado e atenção à saúde vocal da categoria docente. . $^{2,45,11,18 .}$

Mas a voz do professor tem outro sentido na educação: configura importante elemento na relação ensino-aprendizagem. Assim, precisa ser reconhecida e trabalhada também na perspectiva do contexto do processo educativo e dos modos de interação professor-alunos (que perpassam os olhares, os gestos, as linguagens, as palavras, as vozes, as emoções) que se dão nos acontecimentos e práticas educacionais. ${ }^{7} \mathrm{Cabe}$, então, comentar que as percepções identificadas na presente pesquisa não contemplaram a funcionalidade da voz na construção de processos interativos e comunicativos saudáveis e favoráveis ao processo de ensino-aprendizagem.

Assim, o estudo evidencia dois tipos de demandas/necessidades: (1) promoção da saúde vocal e (2) ampliação das percepções sobre a voz na qualidade das interações e comunicações do processo educativo. Desta maneira, a voz do professor deve ser trabalhada no conjunto da expressividade oral e corporal do educador. ${ }^{7}$

Os resultados das categorias "Usos da voz na profissão" e "Condições e organização do trabalho docente" (diálogo com alunos, ambiente ruidoso) confirmam as demandas/necessidades acima citadas e mostram que a funcionalidade da voz do professor apresenta-se distorcida, uma vez que está mais voltada para a disciplina e chamada de atenção dos alunos do que para processos dialógicos, interativos e comunicativos no contexto do processo de ensino-aprendizagem.

Destaca-se, aqui, que o emprego da estratégia de hipersolicitação vocal - uso da voz em forte intensidade - configura um comportamento de risco para a saúde vocal. ${ }^{2,19}$ A elevação da intensidade vocal ocorre, muitas vezes, em contextos de tentativa 
de comunicação em ambientes ruidosos, com elevado número de alunos, como forma de superar o ruído ambiental e manter a atenção dos alunos, melhorar a disciplina e fazer-se ouvido.?

Os problemas e as dificuldades de diálogo, de relacionamento e de interação entre professor e alunos foram apontados como fatores determinantes e intervenientes na saúde vocal, em estudos nas redes pública e privada de ensino. ${ }^{2,13}$

A necessidade de obter a atenção dos alunos encontra-se no cerne da questão que envolve o uso da voz docente, o que se relaciona com a própria condição da atividade e da constituição da subjetividade do ser professor.

Diversos são os fatores estressantes no contexto escolar. ${ }^{20}$ Neste trabalho destacam-se as dificuldades de lidar com a classe, de manter a disciplina, de comunicar conceitos, a baixa motivação e o mau comportamento dos alunos, dentre outros, que envolvem diretamente as demandas de uso vocal.

Assim, os embates e os esforços empreendidos no enfrentamento das dificuldades de obter a atenção dos alunos, manter a disciplina, lidar com incidentes envolvendo comportamentos indadequados e desafiadores dos alunos e estabelecer o diálogo em sala de aula - muitas vezes sem sucesso geram sofrimentos ao trabalhador professor que envolve sentimentos negativos, como frustração e raiva, e levam ao desgaste, estresse e outros problemas de saúde. , 20-22 $^{2}$

Assim, afirma-se a necessidade de que a atenção para a saúde do professor, no contexto do seu trabalho, dê-se a partir de uma perspectiva ampliada - que não se restringe à questão da saúde vocal ${ }^{7}$ nem tampouco ao estresse e à saúde mental -, mas que seja orientada no sentido de buscar ampliar a compreensão sobre os processos que levem ao bem-estar docente e, consequentemente, à qualidade do ensino ofertado. ${ }^{20}$

Além disso, outra questão que merece destaque é a maneira como a voz é compreendida. Sem negar o fato de que a voz precise ser entendida a partir da sua vertente orgânica (qualidade vocal/alterações e distúrbios), destaca-se a importância de que as intervenções e práticas fonoaudiológicas, ao dirigirem-se à categoria docente, esforcem-se para entender e favorecer processos de entendimento da voz também em sua perspectiva psicossocial de expressividade. ${ }^{7}$

Quanto aos resultados da categoria "Cuidados com a voz", cabe comentar que a ingestão de dois litros de água por dia é um importante fator na conservação da saúde vocal; no entanto, nota-se que a hidratação é praticada pelos professores de maneira não sistemática e insuficiente, o que corrobora estudos anteriores. ${ }^{2,12,23}$

Outras estratégias mencionadas, como redução do grito e fazer uso do microfone e amplificação sonora, são úteis para minimizar o desgaste, melhorar o desempenho vocal, facilitar a comunicação e proteger a saúde voz do professor no espaço escolar. ${ }^{24-26}$

Os sujeitos têm conhecimento de alguns cuidados, mas eles são insuficientes para o bem-estar vocal e a promoção da saúde, levando em conta sua condição de sujeitos que fazem uso profissional da voz. Outras formas de cuidados permanecem fora do conhecimento e da realidade do cotidiano de vida e trabalho docente - o que indica a necessidade de outros estudos para melhor compreender os fatores que impactam no cuidado vocal docente. 
Os sujeitos relacionaram a saúde e os comportamentos vocais inadequados às condições e organização do trabalho docente, evidenciando, além das dificuldades de interação e diálogo com os alunos, a falta de recursos materiais e de apoio das instituições e órgãos de trabalho, a inadequação e a insalubridade das salas de aula, dentre outros problemas ligados à precarização do ensino que impactam, de forma negativa, a voz, o trabalho, a saúde e a qualidade de vida do professor. A associação entre os distúrbios de voz em professores e problemas relativos ao ambiente, condições e organização do trabalho é indicada na literatura, em uma relação de multifatoriedade, de modo a levar o fonoaudiólogo envolvido com a questão da voz do professor a ampliar seu olhar no sentido de compreender a voz (ou melhor, a saúde do professor) no contexto do trabalho docente.,

Nota-se que os professores, imbuídos por intenções de preservação da voz (no entanto, sem contarem com formação e preparo em relação ao uso e cuidado vocal ou com estrutura de amparo profissional ou institucional que lhes propicie condições e estratégias coletivas para transformações efetivas na realidade de trabalho), acabam buscando soluções individuais, isoladas e reducionistas para seus problemas. $\mathrm{O}$ foco de tais tentativas de solução geralmente se encontra nas adaptações das estratégias didático-pedagógicas e mudança de hábitos e comportamentos vocais. Ora, sem deixar de reconhecer a validade das intenções e tentativas, é preciso levar em conta que estas representam apenas avanços limitados, especialmente porque, em geral, as soluções buscadas apresentam-se contraditórias às demandas de uma relação de ensino e de processos interativos, relacionais e comunicativos eficazes.

As habilidades e competências relacionadas com a voz e a comunicação oral devem ser trabalhadas na formação inicial e continuada de professores, de modo a favorecer a transformação da percepção sobre a voz, as formas de falar e a criação/formação/ difusão de uma cultura do cuidado vocal na relação com as especificidades dos contextos das diferentes instituições e níveis de ensino, escolas, ambientes, recursos, condições e organizações do trabalho docente. ${ }^{7}$ Nesta perspectiva, as instituições formadoras de professores e também as entidades e associações de classe docente teriam um importante papel a desempenhar, apoiando, defendendo e divulgando estes ideários junto à categoria e à sociedade.

Há necessidade de atenção e investimentos por parte dos setores de saúde e de educação, para enfatizar as questões da voz e expressividade, bem como do cuidado e saúde do professor, nas relações destes com a melhoria das condições e qualidade do trabalho docente e do processo de ensino-aprendizagem.

Ações educativas fonoaudiológicas podem constituir-se em espaços sociais favoráveis para a reflexão e a mobilização para mudanças, e é importante destacar que estas devem ser desenvolvidas de maneira articulada com as demandas e as realidades das condições do trabalho docente e voltadas para a melhoria da qualidade de vida dos educadores e para a formação de ambientes saudáveis na escola, de modo a contribuir para fazer do trabalho um espaço gerador de sentimentos de prazer, de realização e de construção de identidades. ${ }^{7,8}$ 


\section{Conclusão}

O estudo mostrou que o processo saúde-doença-cuidado vocal é percebido de maneira restrita e parcial, e que a importância, a funcionalidade e as estratégias de emprego e preservação da voz, às quais recorrem os professores, são contraditórias à qualidade das interações das demandas do processo de ensino-aprendizagem.

Faz-se necessário o investimento em práticas educativas que contribuam para ampliar a percepção e o conhecimento sobre a própria voz e o desenvolvimento da expressividade do professor nas relações com a qualidade do processo de ensino-aprendizagem, bem como para promover uma cultura voltada para o cuidado vocal, a promoção da saúde e a qualidade de vida da categoria docente. Tais práticas devem ocorrer nos contextos da formação inicial do professor (ambientadas em disciplinas nos cursos de licenciaturas) e, também, da formação continuada docente (ambientadas em ações de assessoria), sendo o fonoaudió- logo o profissional destinado a esta função.

Há necessidade de atenção e investimentos por parte dos setores de saúde e de educação, e também das entidades de classe da categoria docente, no sentido de enfatizar as questões da voz e expressividade, bem como o cuidado e saúde do professor em suas relações com a melhoria das condições e qualidade do trabalho docente e do processo de ensino-aprendizagem. Isso requer movimentos para avanço nas políticas públicas de saúde e de educação (com apoio dos profissionais e entidades de classe). Uma perspectiva seria a inclusão, nas matrizes curriculares dos cursos de licenciaturas, de espaços que sistematizem a preocupação com a valorização do educador e dos processos interativos, comunicativos e dialógicos instaurados na relação educativa, locus e instância de uso vocal, e a preocupação com a formação de uma cultura do cuidado e da saúde do trabalhador professor na perspectiva de formação de espaços escolares saudáveis e da melhoria da qualidade das relações educativas.

\section{REFERÊNCIAS}

1. Medeiros A, Barreto SM, Assunção A. Professores afastados da docência por disfonia: o caso de BH. Cad Saúde Coletiva 2006; 14(4): 615-24.

2. Jardim R, Barreto SM, Assunção A. Condições de trabalho, qualidade de vida e disfonia entre docentes. Cad Saúde Pública 2007; 23(10): 2.439-61.

3. Araújo TM, Reis EJFB, Carvalho FM, Porto LA, Reis IC, Andrade JM. Fatores associados a alterações vocais em professoras. Cad Saúde Pública 2008; 24(6): 1229-38.

4. Alves LA, Robazzi MLCC, Marziale MH, Felippe AC, Romano CC. Health disorders and teachers' voices: a workers' health issue. Rev Latino-Am Enferm 2009; 17(4): 566-72.

5. Azevedo LL, Vianello L, Oliveira HGP, Oliveira IA, Oliveira BFV, Silva CM. Queixas vocais e grau de disfonia em professoras do ensino fundamental. Rev Soc Bras Fonoaudiol 2009; 14(2): 192-6.

6. Ceballos AGC, Carvalho FM, Araujo TM, Reis EJFB. Avaliação perceptivo-auditiva e fatores associados à alteração vocal em professores. Rev Bras Epidemiol 2011; 14(2): 285-95.

7. Ferreira LP, Dragone MLS, Giannini SPP, Zambon FC. Atuação fonoaudiológica com professores - da voz ocupacional à voz como recurso do trabalho docente. In: Marchesan IQ, Silva HJ, 
Tomé MC, organizadores. Tratado das especialidades em fonoaudiologia. São Paulo: Gen/Roca; 2014. p. 250-7.

8. Gonçalves CG, Penteado RZ, Silvério KCA. Fonoaudiologia e Saúde do Trabalhador: a questão da saúde vocal do professor. Saúde Rev 2005; 7(15): 45-51.

9. Penteado RZ, Ribas TM. Processos educativos em saúde vocal do professor: análise da literatura da Fonoaudiologia brasileira Rev Soc Bras Fonoaudiol 2011, v. 16, n. 2, p. 233-9.

10. Simões-Zenari $M$, Latorre $M$. Prevalência de alteração vocal em educadoras e sua relação com a auto-percepção. Rev Saúde Pública 2006; v. 40, p. 1013-8.

11. Penteado RZ, Rossi D. Vivência de voz e percepções de professores sobre saúde vocal e trabalho. Saúde em Revista 2006; 8(18): 39-48.

12. Penteado RZ. Relações entre saúde e trabalho docente: percepções de professores sobre saúde vocal. Rev Soc Bras Fonoaudiol 2007;12(1): 18-22.

13. Bragion T, Foltran T, Penteado RZP. Relações entre voz, trabalho e saúde: percepções de professores. Distúrb Comun 2008; 20(3): 319-25.

14. Roy N, Merril MM, Thibeault S, Gray SD, Smith EM. Voice disorders in teachers and the general population: effects on work performance, attendance, and future career choices. J SpeechLanguage and Hearing Res 2004; 47(2): 281-93.

15. Koschkee DL, Rammage L. Voice care in the medical setting. San Diego: Singular, 1997.

16. Penteado RZ, Gonçalves CGO, Silvério KCA, Rossi D, Libardi A, Vieira TPG. Gupos Focais: possibilidades e aplicações para as pesquisas e práticas fonoaudiológicas. Rev Soc Bras Fonoaudiol 2006; 11(2): 124-8.

17. Bardin L. Análise de conteúdo. Brasil: Edições 70; 2011.

18. Behlau M, Zambon F, Guerrieri AC, Roy N. Epidemiology of voice disorders in teachers and non-teachers in Brazil: prevalence and adverse effects. J Voice 2012; 26(5): 9-18 e 665.

19. Vianello L, Assunção A, Gama A. Estratégias implementadas para enfrentar as exigências vocais da sala de aula: o caso das professoras readaptadas por disfonia. Distúrb Comun 2008; 20(2): 163-70.

20. Silveira KA, Enumo SR, Paula KMP, Batista EP. Estresse e enfrentamento em professores: uma análise da literatura. Educ Rev 2014; 30(4): 15-36.

21. Noronha MMB, Assunção AA, Oliveira DA. O sofrimento no trabalho docente: o caso das professoras da rede pública de Montes Claros (MG). Trab Educ Saúde 2010; 6(1): 65-86.

22. Gianinni SPP, Latorre MRDO, Ferreira LP. Distúrbio de voz e estresse no trabalho docente: um estudo caso-controle. Cad Saúde Pública 2012, 28(11): 2115-24.

23. Ferreira LP, Giannini SPP, Figueira S, Silva EE, Karmann DF, Souza TMT. Condições de produção vocal de professores da Prefeitura do Município de São Paulo. Distúrb Comum 2003; 14(2): 275-308.

24. Roy N, Weinrich B, Gray SD, Tanner K, Toledo SW, Dove H, Corbin-Lewis K, et al. Voice amplification versus vocal hygiene instruction for teachers with voice disorders: a treatment outcomes study. J Speech-Language and Hearing Res 2002; 45(4): 625-38.

25. Servilha EAM; Pereira PM. Condições de trabalho, saúde e voz em professores universitários. Rev Ciências Médicas 2008; 17(1): 21-31.

26. Musial P, Dassie-Leite AP, Zaboroski AP, Casagrande RC. Interferência dos sintomas vocais na atuação profissional de professores. Distúrb Comum 2011; 23(3): 335-41.

Submetido em: 2-6-2015

Aceito em: 7-4-2016 